\title{
Evaluating ornamentation of twelve pillared house in Kelantan and Terengganu
}

\begin{abstract}
Kelantan and Terengganu are rich with beautiful carvings and distinctive motifs. Typically, they use motifs of flora, geometry and calligraphy rather than other motifs and also use as a benchmark of local architecture identity in Peninsular Malaysia. This study will present design analysis of carvings and motifs used on twelve pillared house in Kelantan and Terengganu. Carving in twelve pillared house in Kelantan and Terengganu is measured and referred to drawings of the Malay Studies Centre (KALAM) UTM, Skudai. The analysis is focused on some component parts of the houses which has variety of carved motifs types such as the doors and windows, railings, walls, ventilation panels and stairs. Placement of carved motifs will be studied as well as its importance to the aesthetics of a house or even reflect local regional nature of both states.
\end{abstract}

Keyword: Carved motifs in Kelantan and Terengganu; Twelve pillared house 